\title{
Expression of Porcine Acid-labile Subunit (pALS) of the 150-kilodalton Ternary Insulin-like Growth Factor Complex and Initial Characterization of Recombinant pALS Protein
}

\author{
Dong-Hee Lee ${ }^{\dagger}$, Choa Chun ${ }^{\dagger}$, Sang-Hoon Kim* and C. Young Lee* \\ Regional Animal Industry Research Center, Jinju National University, Jinju 660-758, Korea \\ 'Department of Life Science, University of Seoul, 90 Jeonnong-Dong, Seoul 130-743, Korea \\ Department of Biology, Kyunghee University, Seoul 130-777, Korea
}

Received 15 September 2004, Accepted 22 February 2005

\begin{abstract}
Acid-labile subunit (ALS) is a component of the 150-kDa insulin-like growth factor-binding protein-3 (IGFBP-3) complex, which, by sequestering the majority of IGFs-I and -II and thereby prolonging the half-life of them in plasma, serves as a circulating reservoir of IGFs in mammalian species. A pGEX-2T plasmid and a baculovirus expression constructs harboring a coding sequence for glutathione-Stransferase (GST)-porcine ALS (pALS) fusion protein were expressed in BL21(DE3) $E$. coli and Sf9 insect cells, respectively. The expressed protein was purified by glutathione or Ni-NTN affinity chromatography, followed by cleavage of the fusion protein using Factor Xa. In addition, pALS and hIGFBP-3 were also produced in small amounts in the Xenopus oocyte expression system which does not require any purification procedure. A 65-kDa pALS polypeptide was obtained following the prokaryotic expression and the enzymatic digestion, but biochemical characterization of this polypeptide was precluded because of an extremely low expression efficiency. The baculovirusas well as Xenopus-expressed pALS exhibited the expected molecular mass of $85 \mathrm{kDa}$ which was reduced into 75 and 65 kDa following deglycosylation of Asn-linked carbohydrates by Endo-F glycosidase, indicating that the expressed pALS was properly glycosylated. Moreover, irrespective of the source of pALS, the recombinant pALS and hIGFBP-3 formed a 130-kDa binary complex which could be immunoprecipitated by anti-hIGFBP-3 antibodies. Collectively, results indicate that an authentic pALS protein can be produced by the current expression systems.
\end{abstract}

Keywords: ALS, Expression, IGF, IGFBP-3, Pig

*To whom correspondence should be addressed.

Tel: 82-55-751-3285; Fax: 82-55-753-4422

E-mail: cylee@jinju.ac.kr

\section{Introduction}

More than two thirds of plasma insulin-like growth factors (IGFs)-I and -II are associated with 150-kDa IGF-binding protein (IGFBP)-3 complexes (Jones and Clemmons, 1995; Baxter, 2000). The $85-\mathrm{kDa}$ acid-labile subunit (ALS), which has no intrinsic IGF-binding activity, binds an IGFBP-3:IGF binary complex to form the $150-\mathrm{kDa}$ ternary complex from which the bound IGF is slowly released following limited proteolysis of IGFBP-3 within the ternary complex by the plasma protease activity (Lee and Rechler, 1996; Rechler and Clemmons, 1998) and/or by yet-to-be-known mechanism(s). ALS thus serves to maximize the bioavailability of circulating IGFs by increasing the plasma half-life of them. The role of ALS as a bioavailability modulator of plasma IGF has been well documented in the study of Ueki et al. (2000) in which compared with normal mice, mice with disrupted ALS gene exhibited decreased serum IGF-I concentrations and reduced growth rates resulting from an increased clearance rate and consequently a decreased bioavailibility of circulating IGF. In addition, ALS also serves to protect the host from acute hypoglycemia which can be invoked by an excessive insulinlike action of free IGFs or binary IGF complexes if the ternary IGF complex is insufficiently formed in plasma as in some cases of non-islet cell tumor patients (Zapf, 1993).

Since partial characterization of the ALS protein by Furlanetto (1980) and subsequent purification of it by Baxter et al. (1989), some progress has been made during the past fifteen years in the molecular biological area concerning this protein. ALS cDNAs (Dai and Baxter, 1992; Leong et al., 1992; Delhanty and Baxter., 1996) and/or genes (Boisclair et al., 1996; Delhanty and Baxter, 1997; Rhoads et al., 2000; Suwanichkul et al., 2000; Lee et al., 2001) have been cloned in several species. The ALS gene expression in vivo, as well as its GH-dependence (Ooi et al., 1997), has been localized to the liver (Chin et al., 1994; Dai and Baxter, 1994; Rhoads et 
al., 2000; Lee et al., 2001), which reflects the fact that ALS is primarily a plasma protein. As has been pointed out by Boisclair et al. (2001), only limited biochemical and physiological studies for this protein have been done. For instance, ALS protein has been purified only in the human and rat by a limited number of research groups (Baxter et al., 1989; Baxter, 1990; Baxter and Dai, 1994; Lee and Rechler, 1995). For the past several years we have done molecular biological and biochemical works in porcine ALS (pALS) including cloning of pALS gene (Lee et al., 2001; Jeong et al., 2002; Jin et al., 2004) and biochemical characterization of pALS expressed in Xenopus oocytes (Choi and Lee, 2002; Choi et al., 2004). In the present study, we report the expression and initial biochemical characterization of the recombinant pALS polypeptide.

\section{Materials and Methods}

Prokaryotic expression The pALS5-915 and pALS3-1015 clones of genomic DNA fragments in pCR2.1 TA-cloning vector from a previous study (Lee et al., 2001) contain the entire coding sequence for the mature porcine ALS (pALS) peptide, with a 155-bp overlapping sequence containing an NspI restriction site. A partial insert of pALS5-915 released by BamHI/NspI digestion and a second partial insert of pALS 3-1015 released by NspI/NotI digestion were ligated and inserted into BamHI and NotI sites of pBS plasmid vector (Fig. 1; Stratagene, La Jolla, USA). A 1,755-bp nearly full-length pALS coding sequence of mature pALS peptide spanning from the fifth amino acid through the $\mathrm{COOH}$-terminus was amplified by polymerase chain reaction (PCR) using a 5'-CGC GGATCCATGACGGAGCCCGGGGCGCCATCG-3' forward primer and a 5'-CGCGGATCCTCACAGGTCCAGGCCAGACACAGC-3' reverse primer containing a translation initiation codon (ATG) and a complementary termination codon (TCA), respectively. Both primers were designed to contain a BamHI restriction site (underlined). The PCR condition was $\left[95^{\circ} \mathrm{C} / 2 \mathrm{~min},\left[\left(95^{\circ} \mathrm{C} / 1 \mathrm{~min}\right.\right.\right.$, $55^{\circ} \mathrm{C} / 45 \mathrm{~s}$, and $\left.72^{\circ} \mathrm{C} / 2 \mathrm{~min}\right) \times 30$ cycles, $72^{\circ} \mathrm{C} / 5 \mathrm{~min}$, and $\left.4^{\circ} \mathrm{C}\right]$. The PCR product was digested with BamHI, gel-purified and inserted into the BamHI site of pGEX-2T plasmid expression vector (Amersham Bioscience Korea, Ltd, Seoul, Korea) at the 3 side of glutathione-S-transferase (GST) coding sequence.

The expression construct was transformed into competent BL21(DE3) E. coli cells followed by plating on LB-agar containing IPTG and X-gal and liquid culture of the white colony. A 200-ml starter culture in LB broth obtained by this procedure was added to $2 \mathrm{~L} \mathrm{LB}$ broth and incubated for $3 \mathrm{~h}$ at $37^{\circ} \mathrm{C}$ with vigorous shaking. Expression was induced by adding $1.6 \mathrm{ml}$ of $0.5 \mathrm{M}$ IPTG, after which the E. coli were further incubated for $3 \mathrm{~h}$. The cells were pelleted by centrifugation for $10 \mathrm{~min}$ and suspended with $10 \mathrm{ml}$ of $50 \mathrm{mM}$ phosphate-buffered $(\mathrm{pH} 7.4)$ saline $(200 \mathrm{mM})$ containing $5 \mathrm{mM} \mathrm{MgCl} 2$ and $0.1 \mathrm{mg} / \mathrm{ml}$ lysozyme. After sonication, $5 \mathrm{ml}$ of $20 \%$ Triton X-100 was added to cellular extracts, followed by mixing on a rotating shaker for $30 \mathrm{~min}$ at room temperature and centrifugation for $10 \mathrm{~min}$ at $12,000 \times \mathrm{g}$.

The E. coli lysate was mixed with $1 \mathrm{ml}$ of $50 \%$ glutathioneSepahrose (GSH) bead slurry (Amersham Bioscience Korea, Seoul,

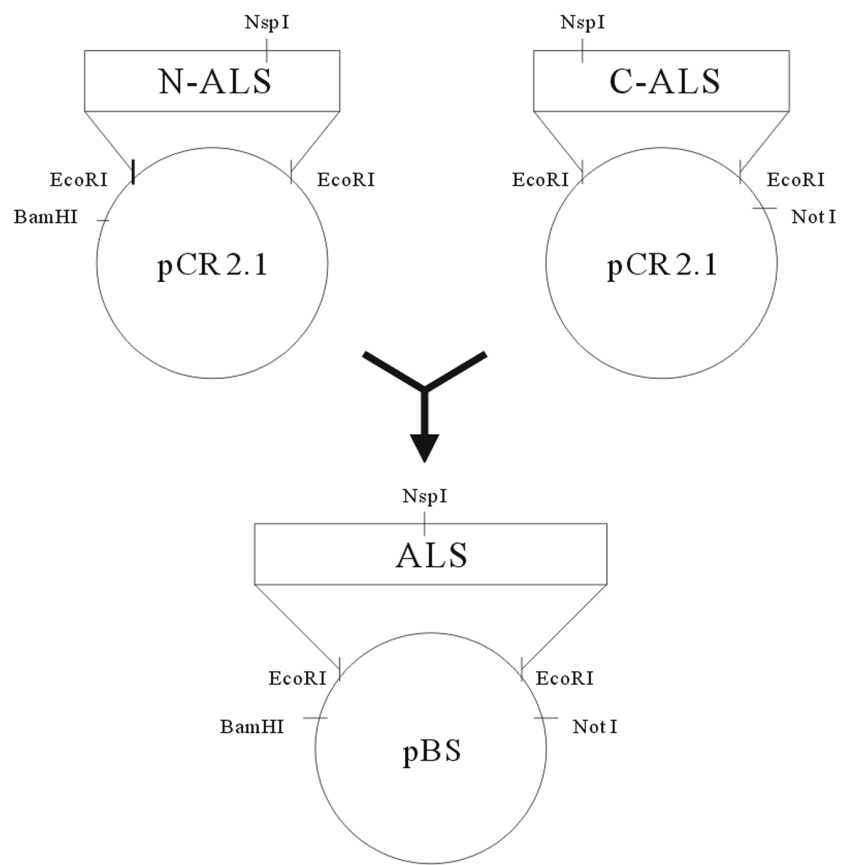

Fig. 1. Cloning of a pALS coding sequence. A BamHI/NspI-cut partial insert of pALS5-915 clone containing a 915-bp 5'-side pALS coding sequence (upper left) and a NspI/NotI-cut partial insert of pALS3-1015 clone containing a 1,015-bp 3'-side coding sequence (upper right) were ligated and inserted into Bam $\mathrm{HI}$ and NotI sites of the pBS vector (bottom). The DNA insert containing the pALS coding sequence in each vector is denoted by a box.

Korea) for $30 \mathrm{~min}$ on a rotating shaker at room temperature. The GSH bead was pelleted by centrifugation for $5 \mathrm{~min}$ at $500 \times \mathrm{g}$, washed with PBS and subjected to SDS- $12 \%$ polyacrylamide gel electrophoresis in multiple lanes under non-reducing conditions. After identifying the presumptive GST-pALS fusion protein band by Coomassie staining of a lane, unstained fusion protein was eluted from the SDS-PAGE gel for $5 \mathrm{~h}$ using an electro-eluter (Model 422; Bio-Rad, Hercules, USA) following manufacturer's instruction. The eluted fusion protein was cleaved by incubation with Factor $\mathrm{Xa}\left(1 \mathrm{U} / \mu \mathrm{l}\right.$; Qiagen, Valencia, USA) at $25^{\circ} \mathrm{C}$ in a 20 $\mathrm{mM}$ Tris-Cl buffer (pH6.5) containing $50 \mathrm{mM} \mathrm{NaCl}$ and $1 \mathrm{mM}$ $\mathrm{CaCl}_{2}$ and was further analyzed by SDS-PAGE.

Preparation of baculovirus expression vector The pALS coding sequence released by EcoRI digestion from the pBS plasmid vector was inserted into the EcoRI site of pFASTBACHTb donor plasmid vector of the baculovirus expression system (Invitrogen, Carlsbad, USA). The orientation of the insert was identified by confirming the sizes on agarose gel of XhoI digestion products of the donor plasmid. The pFASTBACHTb donor plasmid vector harboring the pALS coding sequence was transformed into DH10Bac competent E. coli. After incubating the $E$. coli for $4 \mathrm{~h}$ at $37^{\circ} \mathrm{C}$ in SOC medium, the cells were plated on the LB-agar plate containing terramycin (Tet; $10 \mu \mathrm{g} / \mathrm{ml})$, gentamycin (Gm; $7 \mu \mathrm{g} / \mathrm{ml})$, kanamycin (Kan; $50 \mu \mathrm{g} /$ $\mathrm{ml})$, IPTG $(40 \mu \mathrm{g} / \mathrm{ml})$ and X-gal $(100 \mu \mathrm{g} / \mathrm{ml})$, followed by incubation for 24 to $48 \mathrm{~h}$ at $37^{\circ} \mathrm{C}$. Positive (white) colonies were 
cultured in LB broth and their recombinant bacmid $(>150 \mathrm{kDa})$ was extracted using a Large-Construct DNA extraction kit (Qiagen, Chatsworth, USA). Orientation of the pALS coding sequence within the recombinant bacmid was also identified by confirming the calculated sizes of the bacmid PCR products on agarose gel. The PCR [0.5 $\mu \mathrm{g}$ bacmid DNA, $0.2 \mathrm{mM}$ dNTPs, $0.4 \mu \mathrm{M}$ each primer, $1.25 \mathrm{U} \mathrm{Taq}$ polymerase, $25 \mathrm{mM} \mathrm{MgCl} ; 94^{\circ} \mathrm{C}$ for $3 \mathrm{~min}$, $\left(94^{\circ} \mathrm{C}\right.$ for $30 \mathrm{~s}, 52$ or $54^{\circ} \mathrm{C}$ for $45 \mathrm{~s}$, and $72^{\circ} \mathrm{C}$ for $\left.1 \mathrm{~min}\right) \times 30$ cycles, $72^{\circ} \mathrm{C}$ for $10 \mathrm{~min}$, and $4^{\circ} \mathrm{C}$ ] was performed using M13/pUC primers and an oligonucleotide [5'-CCTGCGGCCCCGCACC TTCA-3'] corresponding to \#948 to \#967 of pALS cDNA.

The $\mathrm{Sf} 9$ insect cells were incubated in T-25 flask containing $5 \mathrm{ml}$ of TNM-FH medium (Invitrogen) containing neither serum nor antibiotic for $18 \mathrm{~h}$ at $27^{\circ} \mathrm{C}$ and washed copiously with cold PBS before transfection. The recombinant bacmid $(4 \mu \mathrm{g})$ in $12 \mu \mathrm{l}$ BellFectin reagent (Gibco-BRL, Gaithersburg, USA) was transfected into $1.5 \times 10^{6}$ Sf9 insect cells according to manufacturer's instruction. The Sf9 cells were further incubated at $27^{\circ} \mathrm{C}$ for $5 \mathrm{~h}$ in serum-free TNM-FH medium followed by 72-h incubation in the medium containing $10 \%$ fetal bovine serum and antibiotics (50 U penicillin and $50 \mu \mathrm{g} / \mathrm{ml}$ streptomycin). Cultured Sf9 cells were centrifuged at $9,000 \mathrm{rpm}$ for $10 \mathrm{~min}$, after which supernatant containing viruses released from the cells was collected. The cell pellet was lysed by freezing and thawing three times using liquid nitrogen and centrifuged for $5 \mathrm{~min}$ at 12,000 rpm. The supernatant was pooled with the previously collected conditioned culture medium and the mixture was designated 'P-1' viral stock. A 'P-2' viral stock was obtained following 72- to 96 -h culture of $3 \times 10^{6}$ Sf6 cells which had been transfected with 1-ml P-1 viral stock in T25 flask; P-3 and P-4 viral stocks were obtained in a virtually identical way following transfection of the insect cells with P-2 and P-3 viral stocks, respectively.

Expression and purification of eukaryotic GST-pALS fusion protein The P-4 viral stock was used for all transfections into the Sf6 cells for pALS expression, based on preliminary results in which, of the four sequential viral stocks, P-4 yielded the greatest amount of expressed protein following the transfection. Typically, 6 to $7 \times 10^{6} \mathrm{Sf}$ cells which had been incubated at $27^{\circ} \mathrm{C}$ for $18 \mathrm{~h}$ in $\mathrm{T}-$ 75 flask in TNM-FH medium received a $0.75-\mathrm{ml}$ P-4 viral stock in 10 -ml TNM-FH medium, followed by further incubation at $27^{\circ} \mathrm{C}$ for $48 \mathrm{~h}$. Both the conditioned culture medium and the lysate of the cultured cells were collected and pooled as previously described. The GST-pALS fusion protein was also expressed in $10-\mathrm{L}$ culture at a density of $2 \times 10^{6}$ cells $/ \mathrm{ml}$ basically as described above.

The recombinant GST-pALS fusion protein was purified by NiNTN affinity chromatography by virtue of the six-histidine tag located in front of the GST peptide. The GST-pALS preparation was loaded at a $0.5 \mathrm{ml} / \mathrm{min}$ flow rate onto $1-\mathrm{ml} \mathrm{Ni-NTN}$ resin (Bio$\mathrm{Rad})$ which had been packed in a $10-\mathrm{ml}$ column and preequilibrated with buffer A [20 mM Tris- $\mathrm{HCl}(\mathrm{pH} 8.5), 500 \mathrm{mM}$ $\mathrm{KCl}, 20 \mathrm{mM}$ imidazole, $5 \mathrm{mM}$ 2-mercaptoethanol, $10 \%$ glycerol] at $4^{\circ} \mathrm{C}$. After washing the column sequentially with ten and two resin volumes of buffers A and B [20 mM Tris- $\mathrm{HCl}(\mathrm{pH} 8.5), 1 \mathrm{M} \mathrm{KCl}, 5$ $\mathrm{mM}$ 2-mercaptoethanol, $10 \%$ glycerol], respectively, the retentate was eluted with an elution buffer [Tris- $\mathrm{HCl}(\mathrm{pH} 8.5), 100 \mathrm{mM}$ imidazole, $5 \mathrm{mM}$ 2-mercaptoethanol, $10 \%$ glycerol]. The eluate was collected in 1.5-ml fractions and fractions containing the fusion protein were pooled after confirmation of the presence of the fusion protein by SDS-PAGE and Coomassie staining of an aliquot of each fraction.

In order to remove the GST peptide from the fusion protein, the GST-ALS fusion protein bound to the agarose bead was digested with Factor Xa (Qiagen) at a $10 \mathrm{U} / \mathrm{ml}$ concentration at $25^{\circ} \mathrm{C}$ in a reaction buffer $(20 \mathrm{mM}$ Tris-Cl, pH6.5; $50 \mathrm{mM} \mathrm{NaCl} ; 1 \mathrm{mM}$ $\mathrm{CaCl}_{2}$ ), followed by examination of the digestion product by SDSPAGE and Coomassie staining.

Expression of pALS and hIGFBP-3 in Xenopus oocytes pALS and hIGFBP-3 were expressed in Xenopus oocytes as previously described (Choi and Lee, 2002; Choi et al., 2004). In brief, pALS and hIGFBP-3 mRNAs were synthesized by in vitro transcription using the SP6 promoter from the pAlter plasmid vector (Promega, Madison, USA) into which either a pALS or hIGFBP-3 coding sequence had been inserted and subsequently linearized. The pALS and hIGFBP-3 mRNAs were microinjected separately or together into Xenopus oocytes which were subsequently incubated for $3 \mathrm{~h}$ at $20^{\circ} \mathrm{C}$. In this expression system, proteins translated only from injected mRNAs were shown to be secreted into the culture medium and accordingly, expressed pALS and/or hIGFBP-3 were recovered from conditioned culture medium with no purification procedure.

Biochemical characterization of eukaryotic recombinant pALS To remove Asn-linked carbohydrate residues, approximately 100 $\mu \mathrm{g}$ recombinant pALS was incubated with $1 \mathrm{U}$ Endo-F (New England Biolab, Beverly, USA) in $50 \mu \mathrm{l} \mathrm{G} 7$ reaction buffer $(50 \mathrm{mM}$ sodium phosphate, $\mathrm{pH}$ 7.5) at room temperature. Molecular sizes of the recombinant pALS before and after the deglycosylation were examined by SDS-PAGE followed by Coomassie staining.

The ability of the recombinant pALS to form a binary complex with hIGFBP-3 was examined by affinity cross-linking and immunoprecipitation with hIGFBP-3 antibodies following incubation of the two recombinant proteins (Choi et al., 2004). Briefly, approximately $10 \mu \mathrm{g}$ recombinant baculovirus- or the oocyteexpressed pALS and $5 \mu \mathrm{g}$ recombinant hIGFBP-3 produced by the oocyte were incubated for $6 \mathrm{~h}$ at $25^{\circ} \mathrm{C}$. The pALS:hIGFBP-3 binary complex was cross-linked for $30 \mathrm{~min}$ at room temperature following addition of disuccinimidyl suberate (Pierce Chemical Co., Rockford, USA) to a final concentration of $0.25 \mathrm{mM}$. After quenching the cross-linking reaction with a Tris buffer and addition of rabbit antiserum to hIGFBP-3 (Upstate Biotechnology, Lake Placid, USA) to a $1: 500$ final dilution, the reaction mixture was incubated for $6 \mathrm{~h}$ at $25^{\circ} \mathrm{C}$. The antigen:antibody complex was precipitated by using protein A-agarose (Bio-Rad) followed by SDS-PAGE and phosphoimaging.

\section{Results}

Expression and purification of recombinant pALS The GST-pALS fusion protein was initially expressed in E. coli cells. The expressed recombinant fusion protein was purified by glutathione-Sepharose affinity chromatogoraphy, SDSPAGE and subsequent electro-elution from the gel, cleavage with Factor Xa and a second SDS-PAGE and electro-elution 


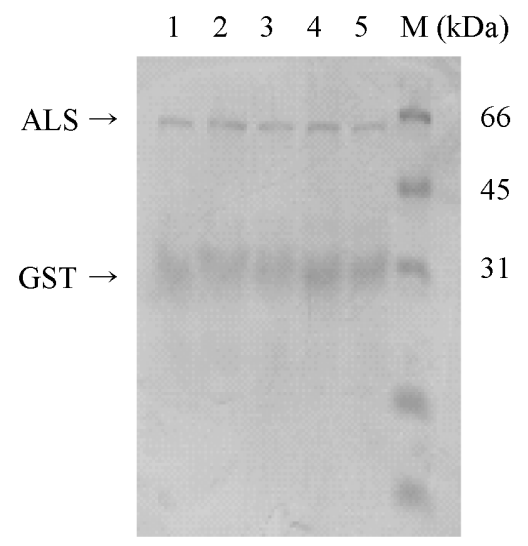

Fig. 2. SDS-PAGE and Coomassie blue staining following cleavage of the recombinant GST-pALS fusion protein. The GSTpALS fusion protein, which had been eluted from the gel after SDS-PAGE preceded by glutathione affinity chromatography of the expressed protein, was cleaved with Factor $\mathrm{Xa}$ and subjected to a second SDS-PAGE, followed by Coomassie blue staining. Lanes $1 \sim 5$, cleaved fusion protein; $\mathrm{M}$, molecular mass standards.

of pALS peptide. Shown in Fig. 2 is an approximately $65-\mathrm{kDa}$ pALS polypeptide of expected size prior to electro-elution from the gel for final purification. The yield of recombinant pALS was approximately $1 \mu \mathrm{g} / \mathrm{L}$ culture. For overcoming the low yield of protein production, we tried to use the baculovirus expression system and obtain the GST-pALS fusion protein.

To make a eukaryotic expression construct, the pALS coding sequence which had been inserted into pBS plasmid vector during the prokayotic expression was trans-positioned into the pFASTBACHTb transfer vector of the baculovirus expression system. The translocation of pALS coding sequence from the transfer vector to the bacmid (baculovirus DNA) was induced in competent DH10Bac competent $E$. coli cells by DNA recombination which was confirmed by an insert-specific PCR-amplification of the bacmid (Fig. 3). The GST-pALS fusion protein expressed from the recombinant bacmid in Sf9 insect cells was purified by glutathione affinity chromatography, after which the ALS fragment was sliced out of the 115-kDa GST-ALS fusion protein by digestion with Factor Xa. The finally purified ALS protein exhibited the expected $85-\mathrm{kDa}$ molecular mass following SDS-PAGE and Coomassie staining (Fig. 4).

Biochemical characteristics of recombinant pALS Now that ALS is a known glycoprotein containing Asn-linked carbohydrate residues, the recombinant pALS was first subjected to deglycosylation to confirm the authenticity of the recombinant pALS. Following deglycosylation of Asn-linked carbohydrate residues with Endo-F, both baculovirus- and Xenopus ooxyte-expressed pALS exhibited 75- and 65-kDa deglycosylated forms as well as the 85-kDa native form (Fig. 5).

The ability of the recombinant purified pALS to form a
(A)

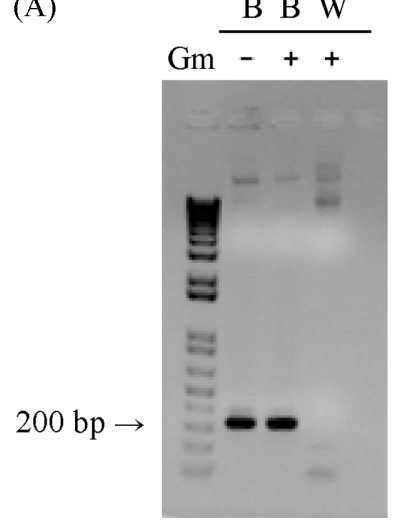

(B)

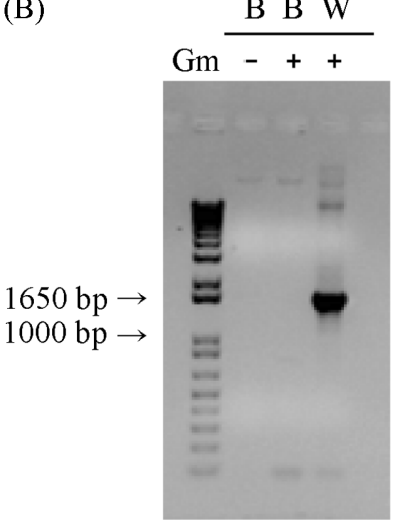

Fig. 3. Agarose gel electrophoresis and ethidium bromide staining of DNA products of pALS insert-specific PCR using the recombinant bacmid DNA as template. The pFastBacHTb donor plasmid vector containing an insert of pALS coding sequence was transformed into DH10BAC competent E. coli cells harboring bMON14272 bacmid (baculovirus DNA) and pMON7124 helper plasmid, followed by the 'blue-white' screening on the LB-agar plate containing IPTG and X-gal with or without indicated antibiotics including gentamycin (Gm). DNAs were isolated from blue and white colonies, after which the transposition of the pALS coding sequence from the pFastBacHTb vector to the bacmid was examined by PCR using (A) the M13 forward and reverse primer pair located within the pFASTBACHTb vector sequence and (B) a forward primer within pALS coding sequence corresponding to \#948 to \#967 of pALS cDNA and the M13/pUC reverse vector. The PCR products were electrophorsed on an agarose gel and ethidium bromide-stained. $\mathrm{B}$ and $\mathrm{W}$ indicate blue and white colonies, respectively, on the LB-agar plate. Note the lack of PCR product in Gm-added (+)-W lane in (A) panel because of the impossible synthesis by PCR of a too long calculated size $(\sim 4 \mathrm{~kb})$ of DNA product and the calculated 1,546-bp PCR product in Gmadded $\mathrm{W}$ lane of (B) panel.

binary complex with recombinant hIGFBP-3 was next examined by affinity cross-linking and immunoprecipitation with hIGFBP-3 antibodies following incubation of the two proteins. After a series of these procedures, the recombinant pALS and recombinant hIGFBP-3 exhibited the expected 130-kDa band as well as a $45-\mathrm{kDa}$ and an $85-\mathrm{kDa}$ ones on the SDS-polyacrylamide gel (Fig. 6). The 130-kDa band most likely represents a cross-linked pALS:hIGFBP-3 complex, whereas the $45-\mathrm{kDa}$ band is likely to have been derived from monomeric hIGFBP-3 as well as an hIGFBP-3:pALS binary complex which didn't undergo any intermolecular crosslinking. Likewise, the 85-kDa represents pALS which had been complexed with hIGFBP-3 but was not cross-linked with the former at the next step.

\section{Discussion}

The basic biochemical nature of human ALS (hALS) has been well characterized by Baxter and his colleagues (Baxter 


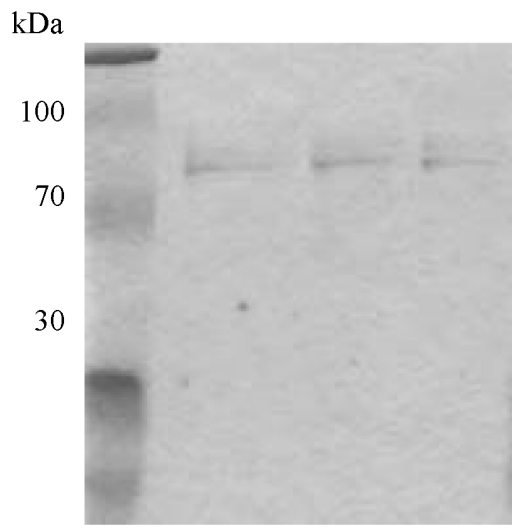

Fig. 4. Coomassie staining of pALS after cleavage of the GSTpALS fusion protein. Following electro-elution of the GST-ALS fusion protein from SDS-polyacrylamide gel, the fusion protein was subjected to cleavage by Factor Xa as described in Materials and Methods. The cleaved protein (right three lanes) was electrophoresed on a SDS-10\% polyacrylamide gel with molecular mass standards (leftmost lane), followed by Coomassie blue staining.

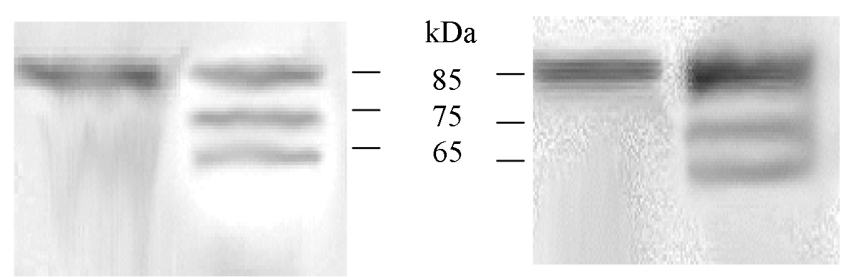

Fig. 5. Purified pALS before and after deglycosylation of Asnlinked carbohydrates. pALS proteins which had been expressed in the baculovirus (left panel) and Xenopus oocyte (right panel) expression systems were electrophoresed on a SDS-10\% polyacrylamide gel before (left lanes) and after (right lanes) digestion with Endo-F, followed by visualization by phosphoimaging. Note the $75-$ and $65-\mathrm{kDa}$ deglycosylated forms of pALS as well as the $85-\mathrm{kDa}$ native form in right lanes.

et al., 1989; Janosi et al., 1999). The 85-kDa hALS protein consists of a $65-\mathrm{kDa}$ peptide core and $20-\mathrm{kDa}$ carbohydrates linked to an unknown number of seven potential Asn residues. The hALS carbohydrates en masse are known to be required for the interaction with IGFBP-3, because total, but not partial, removal of carbohydrate residues from ALS protein abolishes its ability to bind an IGFBP-3:IGF binary complex (Janosi et al., 1999). The ALS protein is also known to bind IGFBP-3 in the absence of IGF in vitro (Barreca et al., 1995; Lee and Rechler, 1995, Choi et al., 2002). Physiological significance of this phenomenon, however, is obscure, because it is not known whether or not IGF binds to preformed IGFBP-3:ALS binary complexes to any significant extent in vivo.

The ALS, by forming $150-\mathrm{kDa}$ ternary complexes with IGFBP-3 and either IGF-I or IGF-II in plasma, serves as a reservoir of circulating IGFs. A second role for this protein as a bioavailability enhancer of plasma IGFs has been well

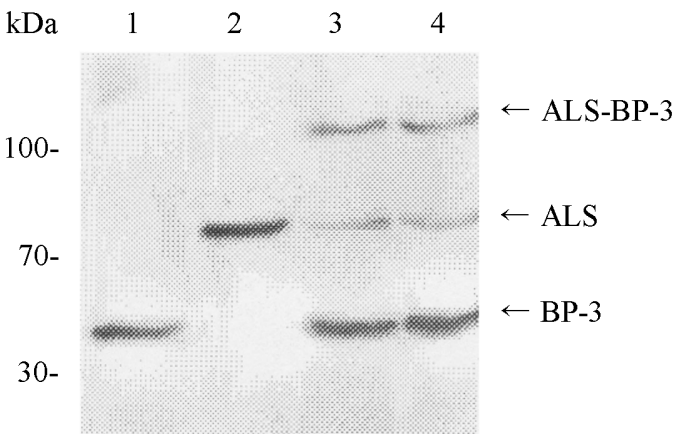

Fig. 6. Complex formation between recombinant pALS and hIGFBP-3: affinity cross-linking and immunoprecipitation. Recombinant pALS protein which had been produced by Xenopus oocytes (lanes 2 and 4) or by the baculovirus expression system (lane 3) was incubated alone (lane 2) or with Xenopus oocyteexpressed hIGFBP-3 (lanes 3 and 4); in lane 1, Xenopus oocyteexpressed hIGFBP-3 was incubated alone. The pALS:hIGFBP-3 complexes were affinity-crosslinked using disuccinimidyl suberate followed by immunoprecipitation with a hIGFBP-3 antiserum, SDS-PAGE and visualization by phosphoimaging.

documented by Ueki et al. (2000) using an ALS genedisrupted mouse model. Interestingly, overexpression of ALS and IGFBP-3 also has been reported to additively decrease the growth rate in transgenic mice (Silha et al., 2001). These results are thus interpreted to implicate that the bioavailability of plasma IGF is maximal at the natural molar ratio of the ternary IGF complex components and hence a disturbance of the equilibrium between the components either towards complex formation by overexpression or towards dissociation by gene targeting is likely to result in a reduced bioavailability of the circulating IGF. It is also known that IGFBP-5 forms the ternary complex with ALS and IGF (Twigg and Baxter, 1998). However, the role of IGFBP-5:ALS complex as a modulator of circulating IGFs seems to be of only a minor significance, because molar concentration of this IGFBP is uncomparably less $(<10 \%)$ than that of IGFBP-3 (Baxter et al., 2002).

The prokaryotic expression of recombinant pALS was tried in the present study primarily to obtain an antigen for the production of antiserum against this protein rather than to confirm the role of its carbohydrate residues. The GST-pALS fusion protein, as intended, could be purified by glutathione affinity chromatography and also be cleaved into GST and pALS peptides of right sizes by the Factor Xa digestion. However, the yield of the prokaryotic pALS was so low that even basic biochemical characterization of the peptide could not be performed, not to speak of the antiserum production. For this reason, all further experiments were performed with the eukaryotic expression system.

The 115-kDa molecular mass of eukaryotic GST-pALS fusion protein and also the $85-\mathrm{kDa}$ mass of pALS derived from the fusion protein are consistent with their expected sizes. The reduction in molecular mass of the $85-\mathrm{kDa}$ purified 
recombinant pALS expressed in both baculovirus-transfected insect cells and Xenopus oocytes into a few deglycosylated variants following Endo-F digestion was also consistent with the result obtained with natural hALS protein (Janosi et al., 1999). These results are interpreted to suggest that the ALS protein contains Asn-linked carbohydrate residues which are susceptible to deglycosylation to varying extents. Moreover, the ability of pALS produced by the baculovirus expression system to form a binary complex with hIGFBP-3 in the absence of IGF was comparable to that of Xenopus oocyteexpressed pALS which was observed in the present as well as previous studies (Choi and Lee, 2002; Choi et al., 2004). These results, which are consistent with previously known characteristics of natural hALS or rALS protein (Baxter et al., 1989; Barreca et al., 1995; Lee and Rechler, 1995; Janosi et al., 1999), indicate that an authentic pALS protein was expressed by our eukaryotic expression systems.

The affinity and binding capacity of the recombinant pALS for IGFBP-3 in the absence and presence of IGF, i.e. Scatchard analysis, have not been determined in the present study because of a limited availability of the recombinant protein. For unknown reasons, the recombinant pALS as well as its fusion protein was so unstable that we were unable to collect an enough amount of pure pALS peptide for the Scatchard analysis. In fact, we attempted the binding assay for the GST-pALS fusion protein in solution, but it did not exhibit any significant affinity for hIGFBP-3 or pIGFBP-3 regardless of the presence or absence of IGF (data not shown). We also generated a rabbit antiserum against the GST-pALS fusion protein which turned out not to recognize pALS (data not shown). It is thus presumed that IGFBP-3-binding site(s) or epitope of pALS was masked by the GST peptide, or the fusion protein was irreversibly damaged during storage due to its inherent instability. In retrospect, we began the biochemical study for pALS several years ago by attempting to purify this protein from serum by the IGF-I-IGFBP-3 'sandwich' affinity chromatography following DEAE-Sephadex A-50 aninon exchange chromatography (Baxter et al., 1989; Baxter and Dai, 1994; Lee and Rechler, 1995). In our experience, however, pALS was never purifiable by this classical method, which also has been concluded by the T. D. Etherton group (personal communication) working in this area at Pennsylvania State University. Regardless of reasons for the failure of this and aforementioned experiments, further biochemical characterization for pALS remains to be pursued.

Acknowledgments This work was supported by Korea Science and Engineering Foundation through Regional Animal Industry Research Center at Jinju National University.

\section{References}

Barreca, A., Ponzani, P., Arvigo, M., Giordano, G. and Minuto, F.
(1995) Effect of the acid-labile subunit on the binding of insulin-like growth factor (IGF)-binding protein-3 to [ $\left.{ }^{125} \mathrm{I}\right] \mathrm{IGF}-\mathrm{I}$. J. Clin. Endocrinol. Metab. 80, 1318-1324.

Baxter, R. C. (1990) Circulating levels and molecular distribution of the acid-labile (alpha) subunit of the high molecular weight insulin-like growth factor-binding protein complex. J. Clin. Endocrinol. Metab. 70, 1347-1353.

Baxter, R. C. (2000) Insulin-like growth factor (IGF)-binding proteins: interactions with IGFs and intrinsic bioactivities. Am. J. Physiol. 278, 967-976.

Baxter, R. C. and Dai, J. (1994) Purification and characterization of the acid-labile subunit of rat serum insulin-like growth factor binding protein complex. Endocrinology 134, 848- 852.

Baxter, R. C., Martin, J. L. and Beniac, V. A. (1989) High molecular weight insulin-like growth factor binding protein complex. Purification and properties of the acid-labile subunit from human serum. J. Biol. Chem. 20, 11843-11848.

Baxter, R. C., Meka, S. and Firth, S. M. (2002) Molecular distribution of IGF binding protein-5 in human serum. J. Clin. Endocrinol. Metab. 87, 271-276.

Boisclair, Y. R., Rhoads, R. P., Ueki, I., Wang, J. and Ooi, G. T. (2001) The acid-labile subunit (ALS) of the $150 \mathrm{kDa}$ IGFbinding protein complex: an important but forgotten component of the circulating IGF system. J. Endocrinol. 170, 63-70.

Boisclair, Y. R., Seto, D., Hsieh, S., Hurst, K. R. and Ooi, G. T. (1996) Organization and chromosomal localization of the gene encoding the mouse acid labile subunit of the insulin-like growth factor binding protein complex. Proc. Natl. Acad. Sci. USA 93, 10028-10033.

Chin, E., Zhou, J., Dai, J., Baxter, R. C. and Bondy, C. A. (1994) Cellular localization and regulation of gene expression for components of the insulin-like growth factor ternary binding protein complex. Endocrinology 134, 2498-2504.

Choi, K-Y., Kyung, Y-J., Lee, C. Y. and Lee, D.-H. (2004) Characterization of insulin-like growth factor-free interaction between insulin-like growth factor binding protein 3 and acid labile subunit expressed from Xenopus oocytes. J. Biochem. Mol. Biol. 37, 153-158.

Choi, K. and Lee, D.-H. (2002) Interaction between acid-labile subunit and insulin-like growth factor binding protein 3 expressed in Xenopus oocytes. J. Biochem. Mol. Biol. 35, 186193.

Dai, J. and Baxter, R. C. (1992) Molecular cloning of the acidlabile subunit of the rat insulin-like growth factor binding protein complex. Biochem. Biophys. Res. Commun. 188, 304309.

Dai, J. and Baxter, R. C. (1994) Regulation in vivo of the acidlabile subunit of the rat serum insulin-like growth factorbinding protein complex. Endocrinology 135, 2335-2341.

Delhanty, P. and Baxter, R. C. (1996) The cloning and expression of the baboon acid-labile subunit of the insulin-like growth factor binding protein complex. Biochem. Biophys. Res. Commun. 277, 897-902.

Delhanty, P. J. D. and Baxter, R. C. (1997) Cloning and characterization of the rat gene for the acid-labile subunit of the insulin-like growth factor binding protein complex. J. Mol. Endocrinol. 19, 267-277.

Furlanetto, R. W. (1980) The somatomedin C binding protein: evidence for a heterologous subunit structure. J. Clin. Endocrinol. Metab. 51, 12-19. 
Janosi, J. B., Firth, S. M., Bond, J. J., Baxter, R. C. and Delhanty, P. J. (1999) N-linked glycosylation and sialylation of the acidlabile subunit. Role in complex formation with insulin-like growth factor (IGF)-binding protien-3 and the IGFs. J. Biol. Chem. 274, 5292-5298.

Jeong, J. H., Kim, J-H., Baik, K-H. and Lee, C. Y. (2002) Cloning of the complementary deoxyribonucleic acid 5 end for porcine acid-labile subunit of the 150-kilodalton insulin-like growth factor complex. J. Agric. Tech. Inst. 15, 187-192.

Jin, E. J., Kim, I. A. and Lee, C. Y. (2004) Cloning of an intron of the gene coding for porcine acid-labile subunit(pALS) of the $150-\mathrm{kDa}$ insulin-like growth factor complex and the 3 untranslated region of pALS complementary DNA and confirmation of pALS gene expression in multiple tissues. $J$. Anim. Sci. Technol. 46, 555-562.

Jones, J. I. and Clemmons, D. R. (1995) Insulin-like growth factors and their binding proteins: biological actions. Endocr. Rev. 16, 3-34.

Lee, C. Y., Kwak, I., Chung, C. S., Choi, W. S., Simmen, R. C. M. and Simmen, F. A. (2001) Molecular cloning of the porcine acid-labile subunit (ALS) of the insulin-like growth factorbinding protein complex and detection of ALS gene expression in hepatic and non-hepatic tissues. J. Mol. Endocrinol. 26, 135144.

Lee, C. Y. and Rechler, M. M. (1995) Purified rat acid-labile subunit and recombinant human insulin-like growth factor (IGF)-binding protein-3 can form a 150-kilodalton binary complex in vitro in the absence of IGFs. Endocrinology 136, 4982-4989.

Lee, C. Y. and Rechler, M. M. (1996) Proteolysis of insulin-like growth factor (IGF) binding protein-3 (IGFBP-3) in 150kilodalton IGFBP complexes by a cation-dependent protease activity in adult rat serum promotes the release of bound IGF-I. Endocrinology 137, 2051-2058.

Leong, S. R., Baxter, R. C., Camerato, T., Dai, J. and Wood, W. I. (1992) Structure and functional expression of the acid-labile subunit of the insulin-like growth factor-binding protein complex. Mol. Endocrinol. 6, 870-876.

Ooi, G. T., Cohen, F. J., Tseng, L. Y., Rechler, M. M. and Boisclair, Y. R. (1997) Growth hormone stimulates transcription of the gene encoding the acid-labile subunit (ALS) of the circulating insulin-like growth factor binding protein complex and ALS promoter activity in rat liver. Mol. Endocrinol. 11, 997-1007.

Rechler, M. M. and Clemmons, D. R. (1998) Regulatory actions of insulin-like growth factor-binding proteins. Trends Endocrinol. Metab. 9, 176-183.

Rhoads, R. P., Greenwood, P. L., Bell, A. W. and Boisclair, Y. R. (2000) Organization and regulation of the gene encoding the sheep acid-labile subunit of the 150-kilodalton insulin-like growth factor-binding protein complex. Endocrinology 141, $1425-1433$.

Silha, J. V., Gui, Y., Modric, T., Suwanichkul, A., Durham, S. K., Powell, D. R. and Murphy, L. M. (2001) Overexpression of the acid-labile subunit of the IGF ternary complex in transgenic mice. Endocrinology 142, 4305-4313.

Suwanichkul, A., Boisclair, Y. R., Olney, R. C., Durham, S. K. and Powell, D. R. (2000) Conservation of a growth hormoneresponsive promoter element in the human and mouse acidlabile subunit gene. Endocrinology 141, 833-838.

Twigg, S. M. and Baxter, R. C. (1998) Insulin-like growth factor (IGF)-binding protein 5 forms an alternative ternary complex with IGFs and the acid-labile subunit. J. Biol. Chem. 273, 6074-6079.

Ueki I., Ooi, G. T., Tremblay, M. L., Hurst, K. R. and Boisclair, Y. R. (2000) Inactivation of the acid labile subunit gene in mice results in mild retardation of postnatal growth despite profound disruptions in the circulating insulin-like growth factor system. Proc. Natl. Acad. Sci. USA 97, 6868-6873.

Zapf, J. (1993) Role of insulin-like growth factor (IGF) II and IGF binding proteins in extrapancreatic tumour hypoglycaemia. J. Intern. Med. 234, 543-552. 